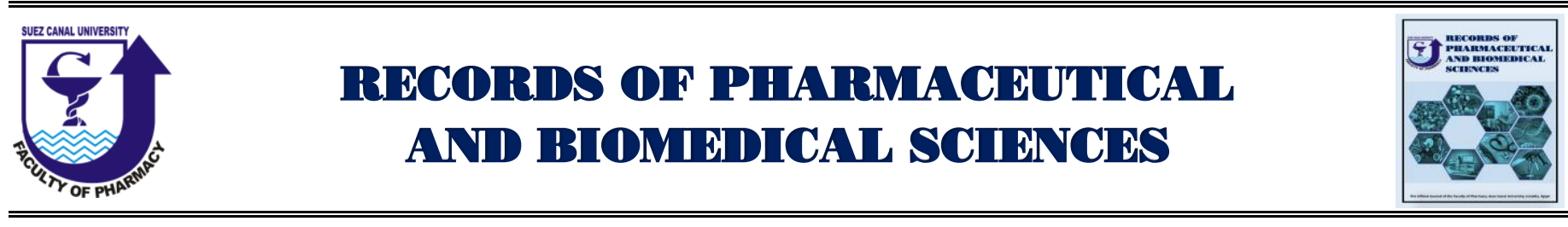

\title{
Phytochemical investigation of Salsola kali extract
}

\section{Tariq Alturkistania ${ }^{\mathrm{a}}$, Marwan Bin Afif ${ }^{\mathrm{a}}$, Rashed Alzahrania ${ }^{\mathrm{a}}$, Reef Alnouno ${ }^{\mathrm{a}}$, Jihan M. Badr ${ }^{b^{*}}$}

${ }^{a}$ Department of Natural Products and Alternative Medicine, Faculty of Pharmacy, King Abdulaziz University, Jeddah 21589, Saudi Arabia

${ }^{b}$ Department of Pharmacognosy, Faculty of Pharmacy, Suez Canal University, Ismailia, 41522, Egypt

Received on: 28.01 .2017

Revised on: $\quad 11.02 .2017$

Accepted on: 15.02.2017

\section{Keywords}

Salsola kali

Anti-inflammatory

Rat paw edema

NMR

\begin{abstract}
The present study focuses on biologically guided fractionation of the extract of Salsola kali, aiming to investigate its anti-inflammatory constituents. The total methanol together with petroleum ether, chloroform and ethyl acetate extracts were investigated for antiinflammatory activity using rat paw edema test. Petroleum ether extract demonstrated the highest activity (60\%) relative to the reference indomethacin. Accordingly, the petroleum ether extract was fractionated using different chromatographic techniques to afford finally 4 compounds identified as lupeol, $\beta$-sitosterol, ursolic acid and $\beta$-sitosterol3-O-glucoside.
\end{abstract}

\section{Introduction}

The promising anti-inflammatory compounds isolated from natural sources belong to a variety of chemical classes including steroids, terpenoids, fatty acids, lipids, polyphenolics, alkaloids, in addition to various miscellaneous compounds (Gautam and Jachak, 2009; Benjamin et al., 2001). The incidence

\footnotetext{
*Corresponding author

Business Tel: $\quad+20-01091332451$

Fax: $\quad+20-64-3561877$

E-mail: $\quad$ gihan96@hotmail.com
}

of inflammatory diseases is becoming common in almost all the countries around the world. Despite of their well-known side effects, non-steroidal antiinflammatory drugs remain the most commonly used to relieve inflammatory pain (Joseph et al., 2010). Natural products and traditional medicines as alternatives to these drugs offer a great hope in the development of efficient agents for treatment of inflammatory diseases (Reynolds et al., 1995). In the present work, the anti-inflammatory activity of a selected plant, Salsola kali will be studied. The fraction that will reveal promising effect will be 
investigated for the main active constituents.

\section{Results and discussion}

Biological evaluation indicated the ability of the petroleum ether fraction to reduce the thickness of the edema induced by carrageenan in rats. The results of anti-inflammatory activity revealed that a gradual decrease in the thickness of the induced edema was clearly detected over time. After $24 \mathrm{hr}$ of dose administration, the petroleum ether fraction produced $60 \%$ of the effect reported by indomethacin. On the other hand, the chloroform, ethyl acetate and methanol extracts displayed $35.0 \%, 20 \%$ and $40 \%$ respectively of change compared to indomethacin (Figure 1). Based on these results, the petroleum ether extract was selected to investigate its major components that may be responsible for this exerted effect. After being subjected to different chromatographic processes including column chromatography (packed with silica gel) and preparative thin layer chromatography, four pure compounds (1-4) were isolated. Compounds $\mathbf{1 - 3}$ were

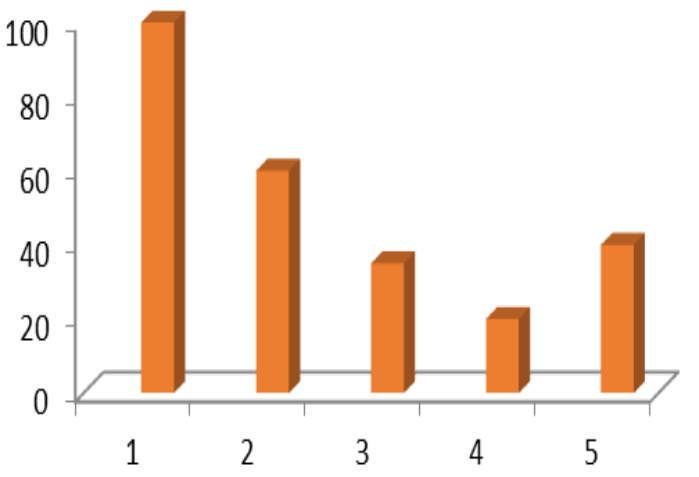

Figure 1: Anti-inflammatory activity of the $S$. kali extracts relative to indomethacin (1: indomethacin, 2: petroleum ether extract, 3: chloroform extract, 4: ethyl acetate extract, 5: methanol extract

analyzed to obtain ${ }^{1} \mathrm{H}$ NMR and ${ }^{13} \mathrm{C}$ NMR data and identified as lupeol, $\beta$-sitosterol and ursolic acid (Figure 2). Compound $\mathbf{4}$ was identified by TLC through comparison of the Rf value with a number of known sterols commonly reported from plants. This comparison proved the identity of compound 4 as $\beta$ sitosterol-3-O-glucoside. These findings can justify the anti-inflammatory activity of petroleum ether extract of the plant Salsola kali. This is due to the large number of previously published reports that confirmed the significant anti-inflammatory activities of the four isolated compounds (Garcia et al., 1999; Saleem, 2009). The significant anti-inflammatory activity produced by the petroleum ether fraction could then be attributed to its sterols' contents.

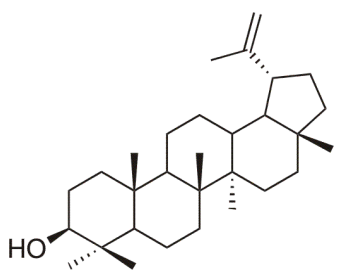

lupeol

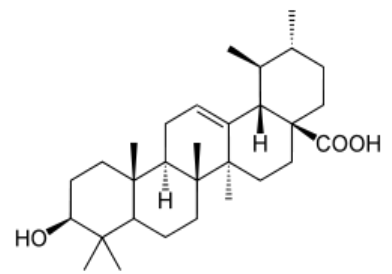

Ursolic acid

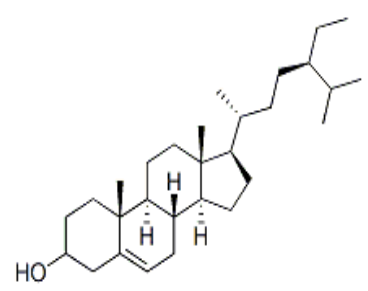

$\beta$-sitosterol

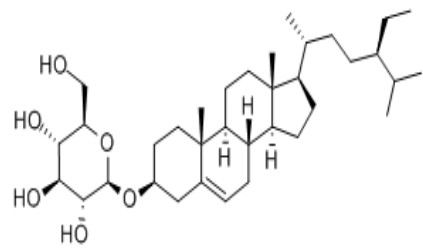

$\beta$-sitosterol-3- $O$-glucoside
Figure 2: Structures of the isolated compounds

\section{Conclusion}

Petroleum ether extract of Salsola kali demonstrated a significant anti-inflammatory activity. A further study for this extract is recommended to evaluate its safety as well as ability for usage as antiinflammatory drug.

\section{Conflict of interest}


The authors report no declaration of conflict of Phytother. Res. 13, 78-80. interest.

\section{Acknowledgements}

No acknowledgement.

\section{References}

Benjamin, H.B., Brian, K., MacKevin, I., Ndubuisi, Elofsson, M., Craig, M., 2001. The antiinflammatory natural product parthenolide from the medicinal herb Feverfew directly binds to and inhibits IкB kinase. Chem. Biol. 8, 759-766.

Garc1'a, M.D., Sa'enz, M.T., Go'mez, M.A., Ferna'ndez, M.A., 1999. Topical antiinflammatory activity of phytosterols isolated from Eryngium foetidum on chronic and acute inflammation models.

Gautam, R., Jachak, S.M., 2009. Recent developments in anti-inflammatory natural products. Med. Res. Rev. 29 (5), 767-820.

Joseph, C.M., Jeffrey, W.B., Adara, M., 2010. Natural anti-inflammatory agents for pain relief. Surg. Neurol. Int. 1, 80.

Reynolds, J.F., Noakes, T.D., Schwellnus, M.P., Windt, A., Bowerbank, P., 1995. Non-steroidal antiinflammatory drugs fail to enhance healing of acute hamstring injuries treated with physiotherapy. S. Afr. Med. J. 85, 517-522.

Saleem, M., 2009. lupeol; A novel anti-inflammatory and anticancer dietary triterpene. Cancer Lett., 285, 109-115. 